\title{
Article \\ The Impact of Radiation Dose to Heart Substructures on Major Coronary Events and Patient Survival after Chemoradiation Therapy for Esophageal Cancer
}

\author{
Xin Wang ${ }^{1,2}$, Nicolas L. Palaskas ${ }^{3}$, Brian P. Hobbs ${ }^{4}$, Jun-ichi Abe ${ }^{3}$, Kevin T. Nead ${ }^{1,5}$, Syed Wamique Yusuf ${ }^{3}$, \\ Joerg Hermann ${ }^{6}$, Anita Deswal ${ }^{3}$ and Steven H. Lin ${ }^{1, *(\mathbb{D})}$
}

1 Department of Radiation Oncology, The University of Texas MD Anderson Cancer Center, Houston, TX 77030, USA; samwang.md@gmail.com (X.W.); ktnead@mdanderson.org (K.T.N.)

2 Department of Radiation Oncology, Tianjin Medical University Cancer Institute and Hospital, National Clinical Research Center for Cancer, Tianjin 300060, China

3 Department of Cardiology, The University of Texas MD Anderson Cancer Center, Houston, TX 77030, USA; nlpalaskas@mdanderson.org (N.L.P.); jabe@mdanderson.org (J.-i.A.); syusuf@mdanderson.org (S.W.Y.); adeswal@mdanderson.org (A.D.)

4 Department of Population Health, Dell Medical School, The University of Texas Austin, Austin, TX 78712, USA; brian.hobbs@austin.utexas.edu

5 Department of Epidemiology, The University of Texas MD Anderson Cancer Center, Houston, TX 77030, USA

6 Department of Cardiovascular Medicine, Mayo Clinic, Rochester, MN 55905, USA; herrmann.joerg@mayo.edu

* Correspondence: shlin@mdanderson.org; Tel.: +1-713-563-8490; Fax: +1-713-563-2866

Citation: Wang, X.; Palaskas, N.L.; Hobbs, B.P.; Abe, J.-i.; Nead, K.T.; Yusuf, S.W.; Hermann, J.; Deswal, A.; Lin, S.H. The Impact of Radiation Dose to Heart Substructures on Major Coronary Events and Patient Survival after Chemoradiation Therapy for Esophageal Cancer. Cancers 2022, 14, 1304. https://doi.org/10.3390/ cancers14051304

Academic Editors: Hajime Isomoto and Hironori Tsujimoto

Received: 28 December 2021 Accepted: 21 February 2022 Published: 3 March 2022

Publisher's Note: MDPI stays neutral with regard to jurisdictional claims in published maps and institutional affiliations.

Copyright: (c) 2022 by the authors. Licensee MDPI, Basel, Switzerland. This article is an open access article distributed under the terms and conditions of the Creative Commons Attribution (CC BY) license (https:// creativecommons.org/licenses/by/ $4.0 /)$.
Simple Summary: Whether it is necessary to evaluate the radiation exposure of cardiac substructures when making radiotherapy plans is one of the current research hotspots. In this cohort study of 355 patients with esophageal cancer, the radiation dose to key coronary substructures such as the left anterior descending artery $\mathrm{V} 30_{\mathrm{Gy}}$ and mean left main coronary artery was closely associated with major coronary events and overall patient survival, and showed better predictive value than the mean heart dose or heart $\mathrm{V} 30_{\mathrm{Gy}}$ recommended by current guidelines. Our findings suggest that, in addition to the whole heart, key coronary substructures should be contoured as organs at risk during radiotherapy plan optimization.

Abstract: Background: There is a paucity of data regarding the association between radiation exposure of heart substructures and the incidence of major coronary events (MCEs) in patients with esophageal cancer (ESOC) undergoing chemoradiation therapy. We studied radiation dosimetric determinants of MCE risk and measured their impact on patient prognosis using a cohort of ESOC patients treated at a single institution. Methods: Between March 2005 and October 2015, 355 ESOC patients treated with concurrent chemoradiotherapy were identified from a prospectively maintained and institutional-regulatory-board-approved clinical database. Dose-distribution parameters of the whole heart, the atria, the ventricles, the left main coronary artery, and three main coronary arteries were extracted for analysis. Results: Within a median follow-up time of 67 months, 14 patients experienced MCEs at a median of 16 months. The incidence of MCEs was significantly associated with the left anterior descending coronary artery (LAD) receiving $\geq 30 \mathrm{~Gy}\left(\mathrm{~V} 30_{\mathrm{Gy}}\right)(p=0.048)$. Patients receiving LAD V30 $\mathrm{Gy} \geq 10 \%$ of volume experienced a higher incidence of MCEs versus the LAD V30 $0_{\mathrm{Gy}}<10 \%$ group $(p=0.044)$. The relative rate of death increased with the left main coronary artery (LMA) mean dose (Gy) $(p=0.002)$. Furthermore, a mutual promotion effect of hyperlipidemia and RT on MCEs was observed. Conclusion: Radiation dose to coronary substructures is associated with MCEs and overall survival in patients with ESOC. In this study, the doses to these substructures appeared to be better predictors of toxicity outcomes than mean heart dose (MHD) or whole-heart $\mathrm{V} 30_{\mathrm{Gy}}$. These findings have implications for reducing coronary events through radiation therapy planning.

Keywords: esophageal cancer; radiotherapy; heart substructure; major coronary events; survival 


\section{Introduction}

Radiation-induced heart disease following thoracic radiotherapy (RT) has long been reported in long-term survivors of breast cancer (BC) [1-4] and Hodgkin's lymphoma (HL) [5-7]. Recently, it was found to be relatively common, with early onset, in patients with non-small cell lung cancer (NSCLC) [8-10] and esophageal cancer (ESOC), despite the high competing risk of death [11]. Radiation can induce a variety of pathological changes, including endothelial dysfunction, inflammation, thrombosis, and cardiac fibrosis, resulting in a variety of cardiotoxicities [12]. Coronary events are one of the important causes of cardiac mortality and morbidity among patients after RT [4,9-11,13].

Typically, the heart as a whole is considered as an organ at risk during thoracic RT, and the mean heart dose (MHD) has generally been used to assess the risk of coronary events in previous studies [4,14]. However, radiobiological responses in various heart substructures may be heterogeneous, and patients may have different cardiotoxicities depending on the radiation dose delivered to each individual cardiac substructure. In a group of patients with HL, Hahn et al. [15] found that the model engaging coronary artery variables was superior to the whole-heart model when analyzing ischemic cardiac events. Since the cardiac radiation exposure in ESOC patients is generally much higher than that in HL, an improved understanding of the dose-cardiotoxicity relationship while taking cardiac substructure volume exposure into consideration is particularly necessary to guide RT delivery.

Currently, the data are limited in terms of the association between radiation dose to heart substructures and major coronary events (MCEs). Our study aims to provide a detailed analysis within a modern cohort of ESOC patients treated with concurrent chemoradiotherapy at conventional radiation doses.

\section{Materials and Methods}

This cohort study comprised 355 patients with biopsy-confirmed esophageal adenocarcinoma or squamous cell carcinoma (SCC) that was treated with RT in prospective, single-institution biomarker or therapeutic trials in which detailed dosimetric data were maintained. Patients in this prospectively maintained database between March 2005 and October 2015 were analyzed (Supplementary Figure S1). All patients in our study underwent esophagogastroduodenoscopy (EGD) with endoscopic ultrasound, computed tomography (CT) of the chest and upper abdomen with contrast, brain imaging (CT or magnetic resonance imaging), and/or positron emission tomography (PET)/CT scans for staging, and were restaged according to the seventh edition of the American Joint Committee on Cancer TNM classification system [16]. Patients with distant metastatic disease, prior or concomitant malignancy, Eastern Cooperative Oncology Group performance status scale (ECOG) scores above 2, or those with incomplete clinical records were excluded. This study was approved by the Institutional Review Board of MD Anderson Cancer Center (protocol code: RCR02-542; date of initial approval: 13 September 2002; updated: 26 March 2021) and the Institutional Review Board waived the requirement for informed consent.

All patients were treated with concurrent chemoradiotherapy strategies, either as a pre-operative treatment or as a curative treatment. About one-third of patients (35.8\%) received induction chemotherapy as part of a clinical trial or due to high-risk disease burden. Chemotherapy regimens typically consisted of fluoropyrimidine and platinumor taxane-based compounds. Ivor Lewis esophagectomy was the most commonly employed surgical approach (79\%). Radiotherapy was delivered with intensity-modulated radiation therapy (IMRT) or proton beam therapy (PBT), and the standard radiation dose was 50.4 Gy (relative biological effectiveness, RBE) in 28 fractions. When the patients were treated in free-breathing mode, four-dimensional computed tomography (CT) simulation was used to track tumor motion throughout the respiratory cycle. All normal structures were contoured on time-averaged CT scans. The IMRT plans were generated by the Pinnacle treatment planning system (version 9.0, Philips, An- 
dover, MA); the PBT plans were generated by the Eclipse planning system (Varian Medical Systems, Liverpool, NY), $92 \%$ of which were completed using passive scattering proton therapy.

The whole heart, the atria, the ventricles, the left main (LMA), and the three main coronary arteries, namely the left anterior descending artery (LAD), the left circumflex artery (LCX), and the right coronary artery (RCA) were included in our analysis. An in-house multi-atlas contouring service (MACS) software program, the auto-contouring accuracy of which was previously verified [17], was used to automatically delineate the cardiac structures on the CT images for treatment planning. The accuracy and consistency of the heart substructures were reviewed for each patient by an experienced radiation oncologist, and necessary modifications were made according to the detailed guideline published by Feng et al. [18]. Dose-volume histograms of the heart were obtained from the delivered RT plan. Based on RTOG 0617 [19], we extracted the mean dose, volume receiving $\geq 5 \mathrm{~Gy}\left(\mathrm{~V} 5_{\mathrm{Gy}}\right)$, volume receiving $\geq 30 \mathrm{~Gy}\left(\mathrm{~V} 30_{\mathrm{Gy}}\right)$, and volume receiving $\geq 50 \mathrm{~Gy}\left(\mathrm{~V} 50_{\mathrm{Gy}}\right)$ for the whole heart and for each cardiac substructure of interest for dosimetric analyses. Planning target volume (PTV) was a geometrical concept used for treatment planning, and defined as enlarged clinical target volume (CTV), which was created from the gross tumor volume (GTV) through volume expansion using individual margins.

The primary endpoint of this study was the occurrence of MCEs after RT [4], which was defined as a diagnosis of myocardial infarction (International Classification of Diseases, 10th Revision, codes 121 to 124), coronary revascularization, or death resulting from ischemic heart disease (codes 120 to 125). These events were verified by physicians who did not know the radiation dose distribution of the whole heart and its substructures and were independently reviewed by cardiologists based on the available source documentation. The time-to-failure endpoint was calculated as the duration from the RT start date to the first occurrence of MCE. Patients without MCEs were right-censored at the last point of contact. The secondary endpoint was overall survival (OS), which was defined as the time from diagnosis to death.

Descriptive statistics were used to characterize the baseline clinic-pathological characteristics of the patients. Overall survival was estimated using the Kaplan-Meier method with Greenwood's formula for interval estimation. Cox proportional hazards regression was used to test for associations between patient clinicopathological characteristics and the study's endpoints (MCE and OS). The competing risk regression method of Fine and Gray [20] was used to adjust the cumulative incidence of MCE for the competing risk of non-cardiac death. Statistical significance was conferred with a $p$-value $<0.05$. Multiple regression analyses included factors identified with a $p$-value $<0.1$ from univariate analysis. Maximally selected rank statistics further explored the utility of applying thresholds to variables identified as statistically significant in regression analysis to classify patients into low-risk versus high-risk groups. Thresholds were selected for individual variables to maximize the log-rank statistic. All analyses were conducted by R (version 3.6.2) and SPSS (version 25.0.0).

\section{Results}

\subsection{Patient Characteristics and MCEs}

In total, 355 ESOC patients fulfilling the predefined criteria were included, with a median age of 62 years (interquartile range, 54 to 68 years). Among them, $89.6 \%$ were male and $88.2 \%$ were white. Baseline characteristics are summarized in Table 1 . Within a median follow-up time of 67 months, 14 patients experienced MCEs at a median of 16 months (interquartile range, 12 to 42$)$, which included myocardial infarction $(n=8)$, coronary artery bypass graft $(n=4)$, and atherosclerosis requiring coronary stent placement $(n=2)$. Details about these patients are provided in Supplementary Table S1. After accounting for non-cardiac death as a competing risk, the cumulative incidence of MCEs is shown in 
Figure 1. Additionally, detailed radiation dose distributions for the cardiac substructures are shown in Supplementary Figure S2.

Table 1. Patients characteristics at baseline.

\begin{tabular}{|c|c|c|c|c|c|c|c|}
\hline \multirow{2}{*}{ Characteristic } & \multicolumn{2}{|c|}{ Total } & \multicolumn{2}{|c|}{ Non-MCEs } & \multicolumn{2}{|c|}{ MCES } & \multirow{2}{*}{$p$-Value } \\
\hline & $\mathbf{N}$ & $\%$ & $\mathbf{N}$ & $\%$ & $\mathbf{N}$ & $\%$ & \\
\hline Sex & & & & & & & 0.647 \\
\hline Male & 318 & 89.6 & 306 & 89.7 & 12 & 85.7 & \\
\hline Female & 37 & 10.4 & 35 & 10.3 & 2 & 14.3 & \\
\hline Age & & & & & & & 0.780 \\
\hline$<65$ & 222 & 62.5 & 214 & 62.8 & 8 & 57.1 & \\
\hline$\geq 65$ & 133 & 37.5 & 127 & 37.2 & 6 & 42.9 & \\
\hline ECOG & & & & & & & 0.586 \\
\hline 0 & 148 & 41.7 & 141 & 41.3 & 7 & 50.0 & \\
\hline $1-2$ & 207 & 58.3 & 200 & 58.7 & 7 & 50.0 & \\
\hline History of Smoking & & & & & & & 0.564 \\
\hline Yes & 236 & 66.5 & 228 & 66.9 & 8 & 57.1 & \\
\hline No & 119 & 33.5 & 113 & 33.1 & 6 & 42.9 & \\
\hline BMI, $\mathrm{kg} / \mathrm{m}^{2}$ & & & & & & & 0.587 \\
\hline$<30$ & 206 & 58.0 & 199 & 58.4 & 7 & 50.0 & \\
\hline$\geq 30$ & 149 & 42.0 & 142 & 41.6 & 7 & 50.0 & \\
\hline History of CAD & & & & & & & 0.708 \\
\hline Yes & 57 & 16.1 & 54 & 15.8 & 3 & 21.4 & \\
\hline No & 298 & 83.9 & 287 & 84.2 & 11 & 78.6 & \\
\hline History of Hyperlipidemia & & & & & & & 0.005 \\
\hline Yes & 200 & 56.3 & 187 & 54.8 & 13 & 92.9 & \\
\hline No & 155 & 43.7 & 154 & 45.2 & 1 & 7.1 & \\
\hline History of Hypertension & & & & & & & 0.090 \\
\hline Yes & 218 & 61.4 & 206 & 60.4 & 12 & 85.7 & \\
\hline No & 137 & 38.6 & 135 & 39.6 & 2 & 14.3 & \\
\hline History of Diabetes & & & & & & & 0.775 \\
\hline Yes & 89 & 25.1 & 86 & 25.2 & 3 & 21.4 & \\
\hline No & 266 & 74.9 & 255 & 74.8 & 11 & 78.6 & \\
\hline Tumor Location & & & & & & & 0.180 \\
\hline Upper/Middle & 38 & 10.7 & 35 & 10.3 & 3 & 21.4 & \\
\hline Distal/GEJ & 317 & 89.3 & 306 & 89.7 & 11 & 78.6 & \\
\hline Pathology & & & & & & & 0.065 \\
\hline Adenocarcinoma & 314 & 88.5 & 304 & 89.1 & 10 & 71.4 & \\
\hline SCC & 41 & 11.5 & 37 & 10.9 & 4 & 28.6 & \\
\hline Clinical T Stage (7th) & & & & & & & 0.377 \\
\hline $\mathrm{T} 1-2$ & 37 & 10.4 & 37 & 10.9 & 0 & 0.0 & \\
\hline T3-4 & 318 & 89.6 & 304 & 89.1 & 14 & 100.0 & \\
\hline Clinical N Stage (7th) & & & & & & & 0.773 \\
\hline No & 113 & 31.8 & 108 & 31.7 & 5 & 35.7 & \\
\hline $\mathrm{N}+$ & 242 & 68.2 & 233 & 68.3 & 9 & 64.3 & \\
\hline Clinical Stage (7th) & & & & & & & 1.000 \\
\hline Stage I/II & 122 & 34.4 & 117 & 34.3 & 5 & 35.7 & \\
\hline Stage III & 233 & 65.6 & 224 & 65.7 & 9 & 64.3 & \\
\hline Induction Chemotherapy & & & & & & & 0.592 \\
\hline Yes & 127 & 35.8 & 123 & 36.1 & 4 & 28.6 & \\
\hline No & 228 & 64.2 & 218 & 63.9 & 10 & 71.4 & \\
\hline Surgery & & & & & & & 0.578 \\
\hline Yes & 215 & 60.6 & 208 & 61.0 & 7 & 50.0 & \\
\hline No & 140 & 39.4 & 133 & 39.0 & 7 & 50.0 & \\
\hline Radiotherapy Modality & & & & & & & 0.397 \\
\hline IMRT & 234 & 65.9 & 223 & 65.4 & 11 & 78.6 & \\
\hline PBT & 121 & 34.1 & 118 & 34.6 & 3 & 21.4 & \\
\hline
\end{tabular}


Table 1. Cont.

\begin{tabular}{|c|c|c|c|c|c|c|c|}
\hline \multirow{2}{*}{ Characteristic } & \multicolumn{2}{|c|}{ Total } & \multicolumn{2}{|c|}{ Non-MCEs } & \multicolumn{2}{|c|}{ MCEs } & \multirow{2}{*}{$p$-Value } \\
\hline & $\mathbf{N}$ & $\%$ & $\mathbf{N}$ & $\%$ & $\mathbf{N}$ & $\%$ & \\
\hline PTV & & & & & & & 1.000 \\
\hline$<600 \mathrm{cc}$ & 173 & 48.7 & 166 & 48.7 & 7 & 50.0 & \\
\hline$\geq 600 \mathrm{cc}$ & 182 & 51.3 & 175 & 51.3 & 7 & 50.0 & \\
\hline $\begin{array}{l}\text { Platin-based } \\
\text { Chemotherapy }\end{array}$ & & & & & & & 0.581 \\
\hline Yes & 144 & 59.4 & 137 & 40.2 & 7 & 50.0 & \\
\hline No & 211 & 40.6 & 204 & 59.8 & 7 & 50.0 & \\
\hline
\end{tabular}

Abbreviations: ECOG, Eastern Cooperative Oncology Group; BMI, body mass index; CAD, coronary artery disease; GEJ, gastroesophageal junction; SCC, squamous cell carcinoma; IMRT, intensity-modulated radiation therapy; PBT, proton beam therapy; PTV, Planning Target Volume.

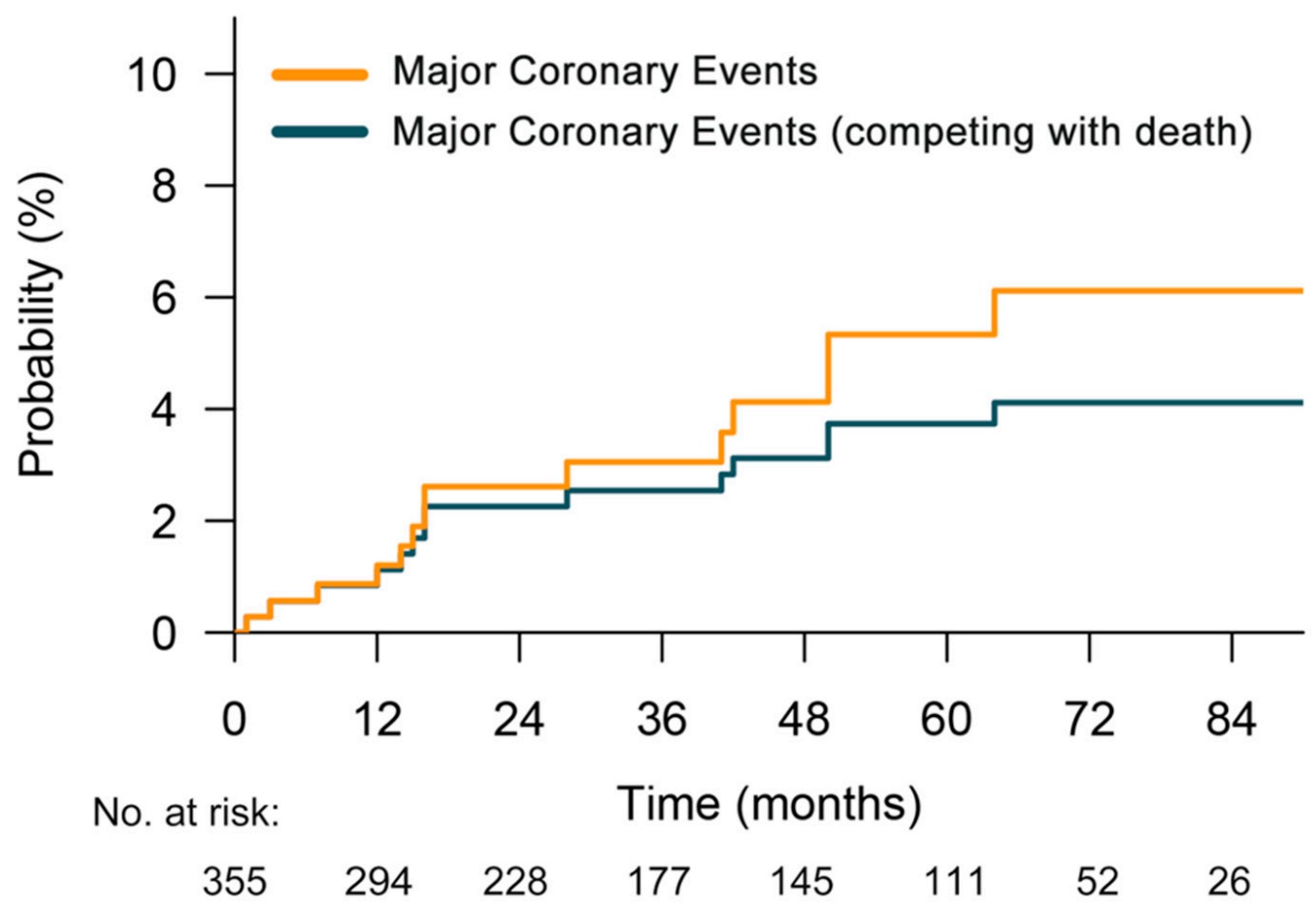

Figure 1. Cumulative incidence plot of major coronary events after chemoradiation (yellow) and major coronary events adjusted for the competing risk of death (green).

\subsection{Risk Factors for MCEs}

On dosimetric analysis, LAD V30 $\mathrm{Gy}(\%)$ (hazard ratio $(\mathrm{HR})=1.025 ; 95 \% \mathrm{CI}, 1.001-1.050$; $p=0.048$ ) was significantly associated with MCEs (Supplementary Table S2). We identified the optimal curve cutoff value of LAD V30 $0_{\text {Gy }}$ for predicting MCE at $10 \%$ (C-index, 0.57 ).

All clinicopathological factors were included in univariate analysis, and those associated with a $p$ value $<0.1$ were included in multivariate analysis. Significant correlations between MCE incidence and history of hyperlipidemia (Yes vs. No, HR $=10.522,95 \% \mathrm{CI}$, $1.373-80.621 ; p=0.023)$ as well as LAD V30 $0_{\mathrm{Gy}}(\geq 10 \%$ vs. $<10 \%, \mathrm{HR}=3.589,95 \% \mathrm{CI}$, $1.124-11.462 ; p=0.031$ ) were identified (Table 2). In patients undergoing RT, a history of hyperlipidemia was associated with an increased risk of developing an MCE (2-y rates, $3.5 \%$ vs. $0.7 \%$; 5 -y rates, $6.3 \%$ vs. $0.7 \% ; p=0.007$ ) (Figure $2 \mathrm{~A}$ ). Compared with patients receiving $\mathrm{LAD} \mathrm{V} 30_{\mathrm{Gy}}<10 \%$, the cumulative incidence of MCEs in patients with LAD V $30_{\mathrm{Gy}} \geq 10 \%$ increased significantly (2-y rates, $4.8 \%$ vs. $2.0 \%$; 5 -y rates, $9.5 \%$ vs. $2.9 \%$; $p=0.044$ ) (Figure 2B). 
Table 2. Univariable and multivariable analysis for time to earliest major coronary events.

\begin{tabular}{|c|c|c|c|c|c|c|}
\hline \multirow{2}{*}{ Variable } & \multicolumn{3}{|c|}{ Univariable Cox Regression Analysis } & \multicolumn{3}{|c|}{ Cox Multivariable Regression } \\
\hline & HR & $95 \%$ CI & $p$-Value & HR & $95 \%$ CI & $p$-Value \\
\hline Sex, Male vs. Female & 0.778 & $0.174-3.476$ & 0.742 & & & \\
\hline Age, $\geq 65$ vs. $<65$ & 1.394 & $0.483-4.023$ & 0.539 & & & \\
\hline ECOG, $1-2$ vs. 0 & 0.754 & $0.264-2.151$ & 0.597 & & & \\
\hline Smoking History, Yes vs. No & 0.693 & $0.240-1.997$ & 0.497 & & & \\
\hline BMI, $\mathrm{kg} / \mathrm{m}^{2}, \geq 30$ vs. $<30$ & 1.290 & $0.452-3.681$ & 0.634 & & & \\
\hline History of CAD, Yes vs. No & 1.735 & $0.483-6.232$ & 0.398 & & & \\
\hline History of Hyperlipidemia, Yes vs. No & 9.748 & $1.275-74.532$ & 0.028 & 10.522 & $1.373-80.621$ & 0.023 \\
\hline History of Hypertension, Yes vs. No & 4.247 & $0.950-18.991$ & 0.058 & & & \\
\hline History of Diabetes, Yes vs. No & 0.853 & $0.238-3.060$ & 0.808 & & & \\
\hline $\begin{array}{c}\text { Tumor Location, Upper/Middle vs. } \\
\text { Distal/GEJ }\end{array}$ & 2.767 & $0.768-9.956$ & 0.119 & & & \\
\hline Pathology, SCC vs. Adenocarcinoma & 3.889 & $1.216-12.436$ & 0.022 & & & \\
\hline Clinical Stage, III vs. I/II & 1.190 & $0.397-3.564$ & 0.756 & & & \\
\hline Induction Chemotherapy, Yes vs. No & 0.705 & $0.221-2.247$ & 0.554 & & & \\
\hline Surgery, Yes vs. No & 0.477 & $0.166-1.368$ & 0.168 & & & \\
\hline Radiotherapy Technology, IMRT vs. PBT & 1.817 & $0.507-6.516$ & 0.360 & & & \\
\hline PTV,$\geq 600 \mathrm{cc}$ vs. $<600 \mathrm{cc}$ & 1.051 & $0.368-2.998$ & 0.926 & & & \\
\hline Platin-based Chemotherapy, Yes vs. No & 1.349 & $0.473-3.849$ & 0.576 & & & \\
\hline LAD, $\mathrm{V}^{3} 0_{\mathrm{Gy}} \geq 10 \%$ vs. $<10 \%$ & 3.101 & $0.972-9.895$ & 0.056 & 3.589 & $1.124-11.462$ & 0.031 \\
\hline
\end{tabular}

Abbreviations: CI, confidence interval; HR, hazard ratio; ECOG, Eastern Cooperative Oncology Group; BMI body mass index; CAD, coronary artery disease; GEJ, gastroesophageal junction; SCC, squamous cell carcinoma; IMRT, intensity-modulated radiation therapy; PBT, proton beam therapy; PTV, Planning Target Volume; LAD, left anterior descending coronary artery.

A

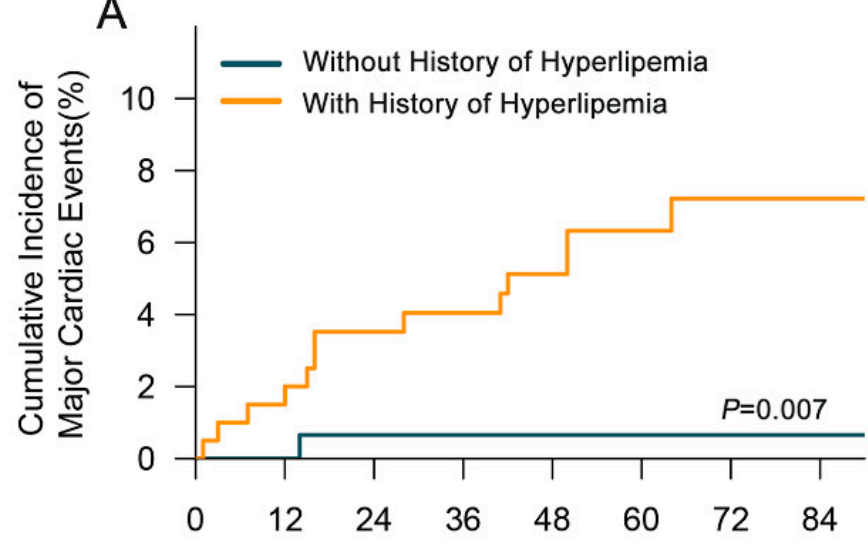

No. at risk:

$\begin{array}{rrrrrrrr}155 & 129 & 102 & 74 & 58 & 46 & 21 & 11 \\ 200 & 165 & 126 & 103 & 87 & 65 & 31 & 15\end{array}$

$\mathrm{B}$

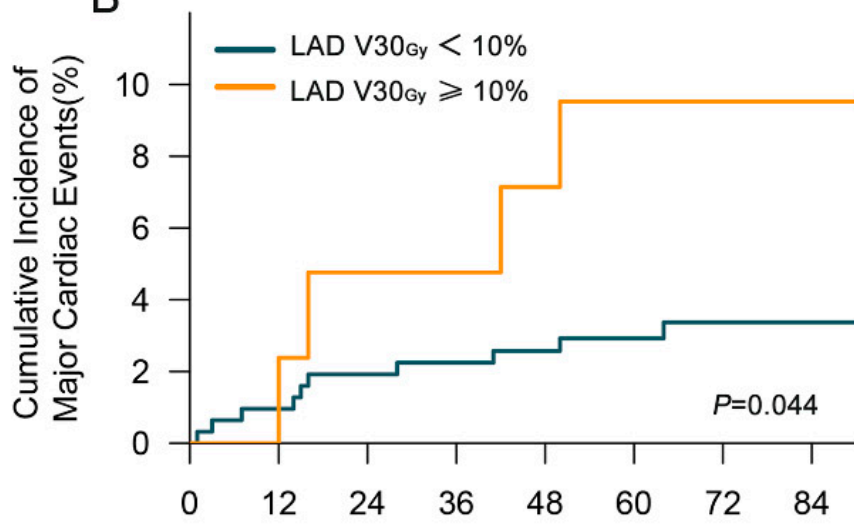

No. at risk: Time (months)

$\begin{array}{cccccccc}313 & 261 & 204 & 158 & 128 & 97 & 46 & 22 \\ -42 & 33 & 24 & 19 & 17 & 14 & 6 & 4\end{array}$

Figure 2. Cumulative incidence of major coronary events (with non-cardiac death as a competing risk) (A) for patients with or without a history of hyperlipidemia (B) for patients delivered to left anterior descending coronary artery (LAD) $\mathrm{V} 30_{\mathrm{Gy}}<10 \%$ and $\geq 10 \%$.

\subsection{Overall Survival}

The median OS was 48 months for the entire group. As indicated by dosimetric analysis, the relative rate of death significantly increased with the mean LMA dose (HR $=1.014$; 95\%CI, 1.005-1.023; $p=0.002$ ) and exhibited better predictive efficacy versus heart $\mathrm{V}^{3} 0_{\mathrm{Gy}}$ and MHD (Supplementary Table S3). The optimal cutoff value of the mean LMA dose was determined to be 20 Gy (C-index, 0.56). 
Clinical stage (III vs. I/II; HR = 1.850; 95\%CI, 1.332-2.571; $p<0.001$ ), surgery (Yes vs. No; HR $=0.542 ; 95 \% C I, 0.407-0.723 ; p<0.001)$, and mean LMA dose ( $\geq 20$ Gy vs. <20 Gy; $\mathrm{HR}=1.488 ; 95 \% \mathrm{CI}, 1.108-1.998 ; p=0.008)$ were identified as independent prognostic factors for OS (Table 3). Patients with an early clinical stage (I/II vs. III; $2-y$ rates, $78.5 \%$ vs. $64.3 \%$; 5 -y rates, $62.4 \%$ vs. 39.7\%; $p<0.001$ ), surgical treatment (Yes vs. No; $2-y$ rates, $79.1 \%$ vs. $54.2 \%$; 5-y rates, $55.9 \%$ vs. $35.1 \% ; p<0.001$ ), and a mean LMA dose < 20 Gy (mean LMA dose < 20 Gy vs. $\geq 20$ Gy; 2 -y rates, $74.3 \%$ vs. $58.6 \%$; 5-y rates, $52.3 \%$ vs. $37.8 \%$; $p=0.001$ ) demonstrated prolonged OS (Figure $3 \mathrm{~A}-\mathrm{C}$ ).

Table 3. Univariable and multivariable analysis for overall survival.

\begin{tabular}{|c|c|c|c|c|c|c|}
\hline \multirow{2}{*}{ Variable } & \multicolumn{3}{|c|}{ Univariable Cox Regression Analysis } & \multicolumn{3}{|c|}{ Cox Multivariable Regression } \\
\hline & HR & $95 \% \mathrm{CI}$ & $p$-Value & HR & $95 \%$ CI & $p$-Value \\
\hline Sex, Male vs. Female & 1.584 & $0.935-2.683$ & 0.087 & & & \\
\hline Age, $\geq 65$ vs. $<65$ & 1.061 & $0.793-1.420$ & 0.688 & & & \\
\hline ECOG, $1-2$ vs. 0 & 0.980 & $0.739-1.299$ & 0.887 & & & \\
\hline Smoking History, Yes vs. No & 1.168 & $0.864-1.578$ & 0.314 & & & \\
\hline BMI, $\mathrm{kg} / \mathrm{m}^{2}, \geq 30$ vs. $<30$ & $0 . .925$ & $0.697-1.229$ & 0.593 & & & \\
\hline History of CAD, Yes vs. No & 1.585 & $1.115-2.252$ & 0.010 & & & \\
\hline History of Hyperlipidemia, Yes vs. No & 0.872 & $0.659-1.155$ & 0.340 & & & \\
\hline History of Hypertension, Yes vs. No & 1.364 & $1.015-1.832$ & 0.039 & & & \\
\hline History of Diabetes, Yes vs. No & 1.296 & $0.950-1.766$ & 0.102 & & & \\
\hline $\begin{array}{c}\text { Tumor Location, Upper/Middle vs. } \\
\text { Distal/GEJ }\end{array}$ & 1.220 & $0.783-1.902$ & 0.379 & & & \\
\hline Pathology, SCC vs. Adenocarcinoma & 1.364 & $0.896-2.076$ & 0.148 & & & \\
\hline Clinical Stage, III vs. I/II & 1.863 & $1.353-2.564$ & 0.000 & 1.850 & $1.332-2.571$ & $<0.001$ \\
\hline Induction Chemotherapy, Yes vs. No & 0.879 & $0.655-1.180$ & 0.390 & & & \\
\hline Surgery, Yes vs. No & 0.557 & $0.420-0.738$ & 0.000 & 0.542 & $0.407-0.723$ & $<0.001$ \\
\hline Radiotherapy Technology, IMRT vs. PBT & 1.047 & $0.776-1.411$ & 0.764 & & & \\
\hline PTV,$\geq 600 \mathrm{cc}$ vs. $<600 \mathrm{cc}$ & 1.319 & $0.995-1.748$ & 0.054 & & & \\
\hline Platin-based Chemotherapy, Yes vs. No & 0.955 & $0.719-1.269$ & 0.751 & & & \\
\hline Mean LMA Dose, $\geq 20$ Gy vs. $<20$ Gy & 1.594 & 1.196 & 0.001 & 1.488 & $1.108-1.998$ & 0.008 \\
\hline
\end{tabular}

Abbreviations: CI, confidence interval; HR, hazard ratio; ECOG, Eastern Cooperative Oncology Group; BMI, body mass index; CAD, coronary artery disease; GEJ, gastroesophageal junction; SCC, squamous cell carcinoma; IMRT, intensity-modulated radiation therapy; PBT, proton beam therapy; PTV, Planning Target Volume; LMA, left main coronary artery.

A

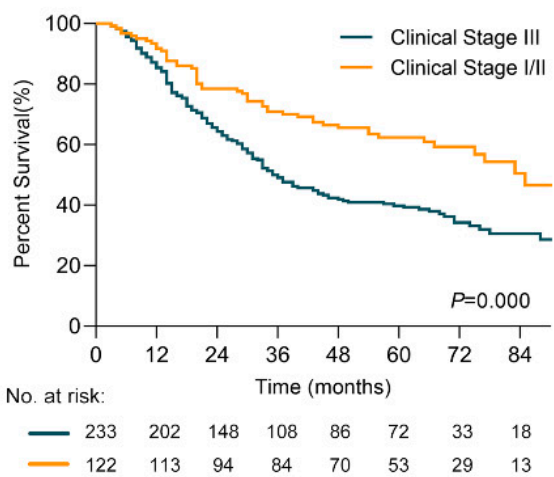

B

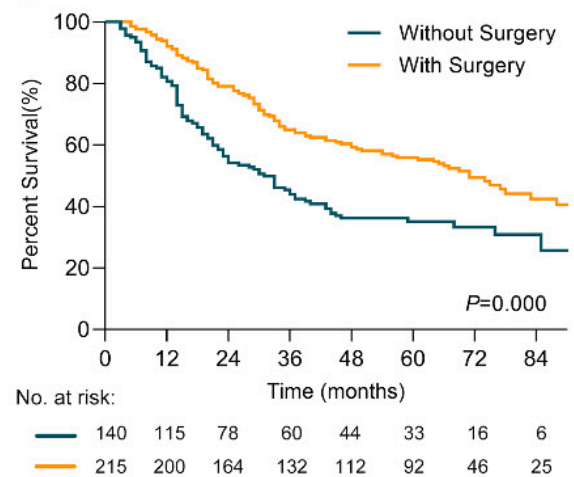

C

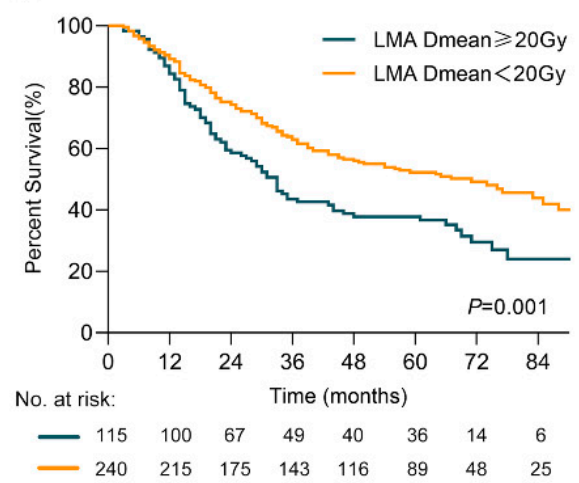

Figure 3. Overall survival rates (A) for patients with clinical stage I/II or III (B) for patients with or without surgery (C) for patients with 20 Gy mean left main coronary artery (LMA) dose cutoff. 


\section{Discussion}

To our knowledge, this is the first study to demonstrate the relationship between MCEs and the radiation exposure of the cardiac substructures in a large cohort of ESOC patients. Our previous study in ESOC, in which the heart was analyzed as an entire organ, showed the correlation between cardiac toxicity and RT. [11]. In this study, we showed that the radiation doses to coronary substructures such as the LAD and LMA are important predictors of subsequent MCEs and OS, and are superior in this prediction compared with the dose to the whole heart as the method of prediction. Our results are consistent with a recent report in a large cohort of non-small cell lung cancer (NSCLC) patients treated with chemoradiation [21]. In that study, the authors found that the LAD V15 $\mathrm{Gy} \geq 10 \%$ was strongly predictive of major adverse cardiac events (MACE), including coronary and heart failure events, cardiac death (adjusted HR 13.9; 95\% CI, 1.23-157.21), and all-cause mortality. The dose cutoff for ESOC being higher than that for NSCLC (V30 ${ }_{G y}$ for ESOC vs. V15 for NSCLC) may be related to the underlying comorbidities of patients with NSCLC vs. those with ESOC. These studies stress the importance of evaluating and avoiding radiation dosing to the key coronary substructures during RT planning for thoracic cancers such as ESOC and NSCLC.

At present, the NCCN Clinical Practice Guidelines in Oncology for Esophageal and Esophagogastric Junction recommended $\mathrm{MHD}$ and heart $\mathrm{V} 30_{\mathrm{Gy}}$ to be the primary indices for the risk assessment of cardiac toxicity. However, highly inhomogeneous doses to the small volumes of the heart may result in diverse heart injuries. Nilsson et al. [22] demonstrated through coronary angiography that the location and severity of coronary artery stenoses were associated with the anticipated hotspot areas for radiation in women with breast cancer. Van et al. [14] found that the MHD-based normal tissue complication probability (NTCP) model for acute coronary events could be improved in terms of calibration and discrimination by replacing MHD with $\mathrm{LV}-\mathrm{V} 5_{\mathrm{Gy}}$. A recent publication from Canada evaluating ischemic-only late cardiotoxicity in a group of HL patients indicated that the best predictive model included age, LAD V5 $5_{\mathrm{Gy}}$, and LCX V20 $\mathrm{Gy}$ as variables [15]. In our study, LAD V30 $0_{\mathrm{Gy}}$ exhibited better prediction of MCEs than either MHD or heart V30 $0_{\mathrm{Gy}}$ and patients with LAD V30 $\mathrm{Gy} \geq 10 \%$ had a significantly increased risk of MCEs, which occurred notably earlier, at a median of 16 months after RT. Accordingly, we recommend that key coronary substructures such as the LAD should be contoured as organs at risk, along with the whole heart, for RT plan optimization.

The other major finding of interest in our study was that among several cardiac risk factors and pre-existing coronary disease, hyperlipidemia was the only independent predictor of MCEs. Hyperlipidemia is a known risk factor for atherosclerosis and increases the incidence of coronary events [23]. Radiation exposure tends to accelerate this process. Mancuso et al. [24] showed that both chronic low dose rate and acute exposure of the coronary arteries to irradiation accelerate atherosclerosis in apolipoprotein E-deficient (ApoE-/-) mice. In the same model of spontaneous atherogenesis, Hoving et al. [25] also observed such an expedited process in the carotid arteries. Notably, in contrast to ApoE-/- mice, none of the irradiated or control wild-type C57BL/6J mice developed atherosclerotic plaques within the 30-week follow-up period. These studies and others [26] that showed a mutual promotion effect between hyperlipidemia and RT on coronary events support the findings of our study. In addition to reducing radiation exposure to the critical coronary substructures, we suggest that patients with a history of hyperlipidemia may benefit significantly from optimized lipid management during and after RT.

Accumulating evidence shows that an excessive cardiac dose potentially contributes to cardiotoxicity, which is indicative of poor OS $[9-11,27,28]$. In the Radiation Therapy Oncology Group (RTOG) 0617 study [19], 74 Gy delivered in 2 Gy daily fractions for patients with stage III NSCLC was no better than $60 \mathrm{~Gy}$, and even potentially harmful, with corresponding increases in heart $\mathrm{V} 5_{\mathrm{Gy}}$ and heart $\mathrm{V} 30_{\mathrm{Gy}}$ that were both significantly associated with a greater risk of death. A close relationship between radiation exposure of the heart and OS was also found in our study. We further demonstrated that the radiation 
dose to the key cardiac substructures, such as LMA, performed as a better predictor of OS than MHD or heart $\mathrm{V} 30_{\mathrm{Gy}}$. Sparing these key substructures, in particular when making RT plans, could potentially improve patient outcomes.

This study should be interpreted in the context of some limitations. First, we were limited by the nature of a retrospective study. Although the events were reviewed from the patients' medical records and adjudicated by cardiologists, we may have undercounted the incidence of MCEs if some of them occurred elsewhere and were not documented in the electronic medical records at MD Anderson Cancer Center (MDACC), or if the patients did not return for follow-up at MDACC. Second, attributed to potential inter-observer variation [29] and the impact of the motion of the heart and its substructures [30], the reconstruction of small structures such as coronary arteries might be less reliable. In order to minimize such uncertainties, we used a validated in-house software program for delineation, and the delineation was checked by a single radiation oncologist with a common contouring guideline. Lastly, given the smaller number of events, further subgroup analysis was not possible. We look forward to validating our findings in larger, prospective, cooperative group clinical trials in the future.

\section{Conclusions}

In conclusion, the radiation dose to the key coronary substructures was closely associated with MCEs and overall patient survival. Therefore, this parameter may be used as a better predictor of coronary events than MHD or heart $\mathrm{V}^{3} 0_{\mathrm{Gy}}$ for ESOC patients. RT plan optimization and dedicated dose constraints for these crucial substructures of the heart may be the best option to reduce cardiac injury and prolong patient survival. Moreover, hyperlipidemia was an aggravating factor for MCEs in the presence of RT in our study, which suggests that optimization of lipid management may be particularly important during and after RT, especially in patients with thoracic cancers such as ESOC.

Supplementary Materials: The following supporting information can be downloaded at: https: / / www.mdpi.com/article/10.3390/cancers14051304/s1, Figure S1: CONSORT diagram; Figure S2: Distribution of median dose indices (A) for heart chambers (B) for left main and three main coronary arteries; Table S1: Details of patients with major coronary events; Table S2: Dosimetric univariable and multivariable analysis for time to earliest major coronary event; Table S3: Dosimetric univariable and multivariable analysis for overall survival.

Author Contributions: Conceptualization, X.W. and S.H.L.; methodology, X.W. and S.H.L.; software, X.W.; validation, X.W., B.P.H. and S.H.L.; formal analysis, X.W.; investigation, X.W., N.L.P., J.-i.A., S.W.Y. and A.D.; resources, X.W. and S.H.L.; data curation, S.H.L.; writing-original draft preparation, X.W.; writing - review and editing, X.W., N.L.P., B.P.H., J.-i.A., K.T.N., S.W.Y., J.H., A.D. and S.H.L.; visualization, X.W.; supervision, X.W. and S.H.L.; project administration, X.W.; funding acquisition, S.H.L. All authors have read and agreed to the published version of the manuscript.

Funding: S.H.L. is supported by NCI Cancer Center Support Grant (CCSG) CA016672, MD Anderson Multidisciplinary Research Program Grant, NIH/NCI 1P01CA261669-01 and the Cancer Prevention \& Research Institute of Texas (RP200670). N.L.P. is supported by the NIH/NCI 1P01CA261669-01, the Cancer Prevention \& Research Institute of Texas (RP200670), and the Sabin Family Foundation Fellowship. J.-i.A. is supported by NIH, U01AI156921. K.T.N. is a Cancer Prevention and Research Institute of Texas (CPRIT) Scholar in Cancer Research and supported by CPRIT RR190077, NCI L30CA253796 and NCI K08CA263313. J.H. is supported by NIH/NCI: CA 233610. A.D. is supported by the Ting Tsung and Wei Fong Chao Distinguished Chair, and has received research support from the MD Anderson Multidisciplinary Research Program Grant.

Institutional Review Board Statement: The study was conducted according to the guidelines of the Declaration of Helsinki and approved by the Institutional Review Board of MD Anderson Cancer Center (protocol code: RCR02-542; date of initial approval: 13 September 2002; updated: 26 March 2021).

Informed Consent Statement: Patient consent was waived due to the retrospective design of this study. 
Data Availability Statement: The data that support the findings of this study are available from the corresponding author (S.H.L.) upon reasonable request.

Conflicts of Interest: The authors declare no potential conflict of interest.

\section{References}

1. Darby, S.C.; McGale, P.; Taylor, C.W.; Peto, R. Long-term mortality from heart disease and lung cancer after radiotherapy for early breast cancer: Prospective cohort study of about 300,000 women in US SEER cancer registries. Lancet Oncol. 2005, 6, 557-565. [CrossRef]

2. Bouillon, K.; Haddy, N.; Delaloge, S.; Garbay, J.R.; Garsi, J.P.; Brindel, P.; Mousannif, A.; Le, M.G.; Labbe, M.; Arriagada, R.; et al. Long-term cardiovascular mortality after radiotherapy for breast cancer. J. Am. Coll. Cardiol. 2011, 57, 445-452. [CrossRef] [PubMed]

3. McGale, P.; Darby, S.C.; Hall, P.; Adolfsson, J.; Bengtsson, N.O.; Bennet, A.M.; Fornander, T.; Gigante, B.; Jensen, M.B.; Peto, R.; et al. Incidence of heart disease in 35,000 women treated with radiotherapy for breast cancer in Denmark and Sweden, Radiotherapy and oncology. J. Eur. Soc. Ther. Radiol. Oncol. 2011, 100, 167-175. [CrossRef] [PubMed]

4. Darby, S.C.; Ewertz, M.; McGale, P.; Bennet, A.M.; Blom-Goldman, U.; Bronnum, D.; Correa, C.; Cutter, D.; Gagliardi, G.; Gigante, B.; et al. Risk of ischemic heart disease in women after radiotherapy for breast cancer. N. Engl. J. Med. 2013, 368, 987-998. [CrossRef] [PubMed]

5. Aleman, B.M.; van den Belt-Dusebout, A.W.; Klokman, W.J.; Veer, M.B.V.; Bartelink, H.; van Leeuwen, F.E. Long-term causespecific mortality of patients treated for Hodgkin's disease. J. Clin. Oncol. 2003, 21, 3431-3439. [CrossRef] [PubMed]

6. $\quad$ van Nimwegen, F.A.; Schaapveld, M.; Janus, C.P.; Krol, A.D.; Petersen, E.J.; Raemaekers, J.M.; Kok, W.E.; Aleman, B.M.; van Leeuwen, F.E. Cardiovascular disease after Hodgkin lymphoma treatment: 40-year disease risk. JAMA Intern. Med. 2015, 175, 1007-1017. [CrossRef] [PubMed]

7. $\quad$ van Nimwegen, F.A.; Schaapveld, M.; Cutter, D.J.; Janus, C.P.; Krol, A.D.; Hauptmann, M.; Kooijman, K.; Roesink, J.; van der Maazen, R.; Darby, S.C.; et al. Radiation Dose-Response Relationship for Risk of Coronary Heart Disease in Survivors of Hodgkin Lymphoma. J. Clin. Oncol. 2016, 34, 235-243. [CrossRef] [PubMed]

8. Ning, M.S.; Tang, L.; Gomez, D.R.; Xu, T.; Luo, Y.; Huo, J.; Mouhayar, E.; Liao, Z. Incidence and Predictors of Pericardial Effusion After Chemoradiation Therapy for Locally Advanced Non-Small Cell Lung Cancer. Int. J. Radiat. Oncol. Biol. Phys. 2017, 99, 70-79. [CrossRef] [PubMed]

9. Dess, R.T.; Sun, Y.; Matuszak, M.M.; Sun, G.; Soni, P.D.; Bazzi, L.; Murthy, V.L.; Hearn, J.W.D.; Kong, F.M.; Kalemkerian, G.P.; et al. Cardiac Events After Radiation Therapy: Combined Analysis of Prospective Multicenter Trials for Locally Advanced Non-SmallCell Lung Cancer. J. Clin. Oncol. 2017, 35, 1395-1402. [CrossRef]

10. Wang, K.; Eblan, M.J.; Deal, A.M.; Lipner, M.; Zagar, T.M.; Wang, Y.; Mavroidis, P.; Lee, C.B.; Jensen, B.C.; Rosenman, J.G.; et al. Cardiac Toxicity After Radiotherapy for Stage III Non-Small-Cell Lung Cancer: Pooled Analysis of Dose-Escalation Trials Delivering 70 to 90 Gy. J. Clin. Oncol. 2017, 35, 1387-1394. [CrossRef]

11. Wang, X.; Palaskas, N.L.; Yusuf, S.W.; Abe, J.I.; Lopez-Mattei, J.; Banchs, J.; Gladish, G.W.; Lee, P.; Liao, Z.; Deswal, A.; et al. Incidence and Onset of Severe Cardiac Events After Radiotherapy for Esophageal Cancer. J. Thorac. Oncol. 2020, 15, 1682-1690. [CrossRef] [PubMed]

12. Tapio, S. Pathology and biology of radiation-induced cardiac disease. J. Radiat. Res. 2016, 57, 439-448. [CrossRef] [PubMed]

13. Darby, S.C.; Cutter, D.J.; Boerma, M.; Constine, L.S.; Fajardo, L.F.; Kodama, K.; Mabuchi, K.; Marks, L.B.; Mettler, F.A.; Pierce, L.J.; et al. Radiation-related heart disease: Current knowledge and future prospects. Int. J. Radiat. Oncol. Biol. Phys. 2010, 76, 656-665. [CrossRef] [PubMed]

14. van den Bogaard, V.A.; Ta, B.D.; van der Schaaf, A.; Bouma, A.B.; Middag, A.M.; Bantema-Joppe, E.J.; van Dijk, L.V.; van Dijk-Peters, F.B.; Marteijn, L.A.; de Bock, G.H.; et al. Validation and Modification of a Prediction Model for Acute Cardiac Events in Patients with Breast Cancer Treated with Radiotherapy Based on Three-Dimensional Dose Distributions to Cardiac Substructures. J. Clin. Oncol. 2017, 35, 1171-1178. [CrossRef] [PubMed]

15. Hahn, E.; Jiang, H.; Ng, A.; Bashir, S.; Ahmed, S.; Tsang, R.; Sun, A.; Gospodarowicz, M.; Hodgson, D. Late Cardiac Toxicity after Mediastinal Radiation Therapy for Hodgkin Lymphoma: Contributions of Coronary Artery and Whole Heart Dose-Volume Variables to Risk Prediction. Int. J. Radiat. Oncol. Biol. Phys. 2017, 98, 1116-1123. [CrossRef] [PubMed]

16. Edge, S.B.; Compton, C.C. The American Joint Committee on Cancer: The 7th edition of the AJCC cancer staging manual and the future of TNM. Ann. Surg. Oncol. 2010, 17, 1471-1474. [CrossRef]

17. Zhou, R.; Liao, Z.; Pan, T.; Milgrom, S.A.; Pinnix, C.C.; Shi, A.; Tang, L.; Yang, J.; Liu, Y.; Gomez, D.; et al. Cardiac atlas development and validation for automatic segmentation of cardiac substructures, Radiotherapy and oncology. J. Eur. Soc. Ther. Radiol. Oncol. 2017, 122, 66-71. [CrossRef] [PubMed]

18. Feng, M.; Moran, J.M.; Koelling, T.; Chughtai, A.; Chan, J.L.; Freedman, L.; Hayman, J.A.; Jagsi, R.; Jolly, S.; Larouere, J.; et al. Development and validation of a heart atlas to study cardiac exposure to radiation following treatment for breast cancer. Int. J. Radiat. Oncol. Biol. Phys. 2011, 79, 10-18. [CrossRef] 
19. Bradley, J.D.; Paulus, R.; Komaki, R.; Masters, G.; Blumenschein, G.; Schild, S.; Bogart, J.; Hu, C.; Forster, K.; Magliocco, A.; et al. Standard-dose versus high-dose conformal radiotherapy with concurrent and consolidation carboplatin plus paclitaxel with or without cetuximab for patients with stage IIIA or IIIB non-small-cell lung cancer (RTOG 0617): A randomised, two-by-two factorial phase 3 study. Lancet Oncol. 2015, 16, 187-199. [PubMed]

20. Fine, J.P.; Gray, R.J. A Proportional Hazards Model for the Subdistribution of a Competing Risk. J. Am. Stat. Assoc. 1999, 94, 496-509. [CrossRef]

21. Atkins, K.M.; Chaunzwa, T.L.; Lamba, N.; Bitterman, D.S.; Rawal, B.; Bredfeldt, J.; Williams, C.L.; Kozono, D.E.; Baldini, E.H.; Nohria, A.; et al. Association of Left Anterior Descending Coronary Artery Radiation Dose With Major Adverse Cardiac Events and Mortality in Patients With Non-Small Cell Lung Cancer. JAMA Oncol. 2020, 7, 206-219. [CrossRef] [PubMed]

22. Nilsson, G.; Holmberg, L.; Garmo, H.; Duvernoy, O.; Sjogren, I.; Lagerqvist, B.; Blomqvist, C. Distribution of coronary artery stenosis after radiation for breast cancer. J. Clin. Oncol. 2012, 30, 380-386. [CrossRef]

23. Malakar, A.K.; Choudhury, D.; Halder, B.; Paul, P.; Uddin, A.; Chakraborty, S. A review on coronary artery disease, its risk factors, and therapeutics. J. Cell Physiol. 2019, 234, 16812-16823. [CrossRef] [PubMed]

24. Mancuso, M.; Pasquali, E.; Braga-Tanaka, I., 3rd; Tanaka, S.; Pannicelli, A.; Giardullo, P.; Pazzaglia, S.; Tapio, S.; Atkinson, M.J.; Saran, A. Acceleration of atherogenesis in ApoE-/- mice exposed to acute or low-dose-rate ionizing radiation. Oncotarget 2015, 6, 31263-31271. [CrossRef] [PubMed]

25. Hoving, S.; Heeneman, S.; Gijbels, M.J.; Poele, J.A.T.; Russell, N.S.; Daemen, M.J.; Stewart, F.A. Single-dose and fractionated irradiation promote initiation and progression of atherosclerosis and induce an inflammatory plaque phenotype in ApoE (-/-) mice. Int. J. Radiat. Oncol. Biol. Phys. 2008, 71, 848-857. [CrossRef]

26. Tribble, D.L.; Barcellos-Hoff, M.H.; Chu, B.M.; Gong, E.L. Ionizing radiation accelerates aortic lesion formation in fat-fed mice via SOD-inhibitable processes. Arterioscler. Thromb. Vasc. Biol. 1999, 19, 1387-1392. [CrossRef]

27. Chun, S.G.; Hu, C.; Choy, H.; Komaki, R.U.; Timmerman, R.D.; Schild, S.E.; Bogart, J.A.; Dobelbower, M.C.; Bosch, W.; Galvin, J.M.; et al. Impact of Intensity-Modulated Radiation Therapy Technique for Locally Advanced Non-Small-Cell Lung Cancer: A Secondary Analysis of the NRG Oncology RTOG 0617 Randomized Clinical Trial. J. Clin. Oncol. 2017, 35, 56-62. [CrossRef] [PubMed]

28. Speirs, C.K.; DeWees, T.A.; Rehman, S.; Molotievschi, A.; Velez, M.A.; Mullen, D.; Fergus, S.; Trovo, M.; Bradley, J.D.; Robinson, C.G. Heart Dose Is an Independent Dosimetric Predictor of Overall Survival in Locally Advanced Non-Small Cell Lung Cancer. J. Thorac. Oncol. 2017, 12, 293-301. [CrossRef] [PubMed]

29. Lorenzen, E.L.; Taylor, C.W.; Maraldo, M.; Nielsen, M.H.; Offersen, B.V.; Andersen, M.R.; O’Dwyer, D.; Larsen, L.; Duxbury, S.; Jhitta, B.; et al. Inter-observer variation in delineation of the heart and left anterior descending coronary artery in radiotherapy for breast cancer: A multi-centre study from Denmark and the UK, Radiotherapy and oncology. J. Eur. Soc. Ther. Radiol. Oncol. 2013, 108, 254-258. [CrossRef] [PubMed]

30. Tan, W.; Xu, L.; Wang, X.; Qiu, D.; Han, G.; Hu, D. Estimation of the displacement of cardiac substructures and the motion of the coronary arteries using electrocardiographic gating. OncoTargets Ther. 2013, 6, 1325-1332. [CrossRef] [PubMed] 